\title{
Increased attention for computer-tailored health communications: an event-related potential study
}

Citation for published version (APA):

Ruiter, R. A. C., Kessels, L. T. E., \& Schmitt, B. M. (2006). Increased attention for computer-tailored health communications: an event-related potential study. Health Psychology, 25, 300-306. https://doi.org/10.1037/0278-6133.25.3.300

Document status and date:

Published: 01/01/2006

DOI:

10.1037/0278-6133.25.3.300

Document Version:

Publisher's PDF, also known as Version of record

Document license:

Taverne

Please check the document version of this publication:

- A submitted manuscript is the version of the article upon submission and before peer-review. There can be important differences between the submitted version and the official published version of record.

People interested in the research are advised to contact the author for the final version of the publication, or visit the DOI to the publisher's website.

- The final author version and the galley proof are versions of the publication after peer review.

- The final published version features the final layout of the paper including the volume, issue and page numbers.

Link to publication

\footnotetext{
General rights rights.

- You may freely distribute the URL identifying the publication in the public portal. please follow below link for the End User Agreement:

www.umlib.nl/taverne-license

Take down policy

If you believe that this document breaches copyright please contact us at:

repository@maastrichtuniversity.nl

providing details and we will investigate your claim.
}

Copyright and moral rights for the publications made accessible in the public portal are retained by the authors and/or other copyright owners and it is a condition of accessing publications that users recognise and abide by the legal requirements associated with these

- Users may download and print one copy of any publication from the public portal for the purpose of private study or research.

- You may not further distribute the material or use it for any profit-making activity or commercial gain

If the publication is distributed under the terms of Article $25 \mathrm{fa}$ of the Dutch Copyright Act, indicated by the "Taverne" license above, 


\title{
Increased Attention for Computer-Tailored Health Communications: An Event-Related Potential Study
}

\author{
Robert A. C. Ruiter, Loes T. E. Kessels, and \\ Bernadette M. Jansma \\ Universiteit Maastricht
}

\author{
Johannes Brug \\ Erasmus University Medical Center
}

\begin{abstract}
The authors tested whether individually tailored health communications receive more attention from the reader than nontailored health communications in a randomized, controlled trial among student volunteers $(N=24)$. They used objective measures of attention allocation during the message exposure. In a between-subjects design, participants had to read tailored or nontailored nutrition education messages and at the same time had to pay attention to specific odd auditory stimuli in a sequence of frequent auditory stimuli (odd ball paradigm). The amount of attention allocation was measured by recording event-related potentials (ERPs; i.e., N100 and P300 ERPs) and reaction times. For the tailored as opposed to the nontailored group, results revealed larger amplitudes for the N100 effect, smaller amplitudes for the P300 effect, and slower reaction times. Resource allocation theory and these results suggest that those in the tailored group allocated more attention resources to the nutrition message than those in the nontailored group.
\end{abstract}

Keywords: computer tailoring, attention, ERP analysis, persuasion

In health education, tailoring has been defined as "any combination of information or change strategies intended to reach one specific person, based on characteristics that are unique to that person, related to the outcome of interest, and have been derived from an individual assessment" (Kreuter, Farrell, Olevitch, \& Brennan, 2000, p. 5). Today it is possible to apply tailoring by use of interactive technology. In such computer tailoring, the combined expertise of health educators is translated into a computer expert system (see Dijkstra \& De Vries, 1999). Empirical studies have found evidence for the hypothesis that persuasive health messages that are computer tailored are more effective in motivating people to self-protective action than nontailored health messages (for a review, see Brug \& De Vries, 1999). Higher personal relevance and thus higher attention and stronger cognitive processing of the health messages have been proposed as important mechanisms for the increased effectiveness of computer-tailored education over traditional nontailored interventions (e.g., Brug, Oenema, \& Campbell, 2003). However, evidence for these working mechanisms is based on self-reports derived after exposure to the message (e.g., Brug, Glanz, Van Assema, Kok, \& Van Breukelen, 1998).

Robert A. C. Ruiter and Loes T. E. Kessels, Department of Experimental Psychology, Universiteit Maastricht, Maastricht, the Netherlands; Bernadette M. Jansma, Department of Neurocognition, Universiteit Maastricht; Johannes Brug, Department of Public Health, Erasmus University Medical Center, Rotterdam, the Netherlands.

Please note that Bernadette M. Jansma formerly published under her maiden name, B. M. Schmitt. We thank Ron Hellenbrand for his technical assistance in setting up the study.

Correspondence concerning this article should be addressed to Robert A. C. Ruiter, Department of Experimental Psychology, Universiteit Maastricht, P. O. Box 616, 6200 MD Maastricht, the Netherlands. E-mail: r.ruiter@psychology.unimaas.nl
A major limitation of these explicit measures is that they require introspection from the participants even though the people may not be aware of the motives that drive their behavior (Wilson, 2002). Furthermore, participants may respond with socially desirable statements. In studying less observable cognitive processes, such as the amount of attention given to personally relevant health information, researchers' use of implicit measures such as reaction times, as well as the high temporal-resolution method of eventrelated potentials (ERPs) that enables assessment of attention processes online within milliseconds after stimulus onset (for an introduction, see Fabiani, Gratton, \& Coles, 2000), has important advantages. In this study, we used reaction time and ERPs measurements, which are generated from a continuous measure of brain activity by means of an electroencephalogram (EEG), to study attention during the exposure to computer-tailored or nontailored nutrition education messages.

\section{Attention and ERP Analysis}

To study attention, we specifically focused on the extent to which participants allocated their attention resources to tailored health communications. In persuasion research, researchers generally believe that attention is a necessary (but not sufficient) condition for effective communication (McGuire, 1985). However, persuasion researchers have largely ignored attention as a dependent variable in evaluation studies. In contrast, attention has been extensively studied in cognitive science and in neuroscience for different modalities, such as visual attention, auditory attention, or cross-modal processing (for reviews, see Mangun \& Hillyard, 1995; Näätänen, 1992). For instance, attention can be disengaged from one process and shifted to another. For example, when speaking with the passenger next to you in the car, you can shift or reallocate your attention away from the speaking process and toward the road and the driving task whenever the traffic situation 
requires your attention. This shift of attention has been addressed in numerous ways. Here we focus on the shift as a reallocation of attention resources based on the theory of resource allocation (for extensive reviews and critical discussion, see Kok, 1997; Sanders, 1997).

Resource allocation theory says that we have limited mental attention resources and whenever we pay more attention to one task (or feature), we will have less attention for another task (or feature). If attention is directed to one stimulus, this attended stimulus is processed with benefits because of the sensory and evaluation gain of the incoming stimuli for the attended stimulus compared with the ignored stimulus. This benefit is usually seen in faster reaction times, in higher percentages of good performances, and in higher amplitudes of ERPs that are sensitive to dividedattention effects.

The relationship between mental resources of attention and ERPs has been discussed especially with regard to two target ERP components, namely the N100 and the P300. Both components show larger amplitudes when the target stimulus is attended to by the participant than when there is less or no attention paid by the participant to the target. The N100 is an early component with negative amplitude that has a maximum peak around $100 \mathrm{~ms}$ after stimulus onset. The N100 is usually interpreted as reflecting the distribution of perceptual resources to task-relevant stimulus processing. The P300, in contrast, is a relatively late positive component that has a maximum peak around $300 \mathrm{~ms}$ after stimulus onset and that is strongly influenced by the task demands that are laid on the participant. The P300, which usually is strongest at centralparietal scalp sites, reflects relatively (compared with the N100) late and thus more controlled attention processes and as such provides an index for a cognitively driven allocation of attention and an update of stimulus processing with working-memory information (e.g., Coull, 1998; Hillyard, Mangun, Woldorff, \& Luck, 1995; Näätänen, 1992).

\section{Overview of the Study and Hypothesis}

In a dual-task paradigm, participants were reading either computer-tailored nutrition education messages (derived from an existing computer-tailoring system, see Brug et al., 1998) or nontailored general nutrition education messages and simultaneously listening to sequences of auditory tones. Although participants had to process both streams of information (auditory and textual), they had to focus attention, that is, allocate the majority of their attention resources, to the auditory task because for this task they carried out an active decision. They were asked to push a button whenever a rare high-frequency tone (i.e., a target) appeared and to withhold the response whenever a standard low-frequency tone (i.e., a nontarget) was presented.

An N100 effect or P300 effect is defined as the difference between the average ERP of the rare conditions minus the average ERP of standard conditions. Attention reallocation processes, in turn, are inferred from the reduction of the N100 effect or P300 effect as a result of greater attention being paid by the participant to a secondary task- here, the reading of a nutrition education message (e.g., Kramer, Wickens, \& Donchin, 1985). In accordance with this view, we assumed that the observed auditory attention effects in the N100 and P300 ERPs can be used as an inverted index of the number of perceptual and cognitive attention re- sources allocated to the reading of the nutrition message. Therefore, in line with theoretical notions that people attend more to personally relevant information (e.g., Petty \& Cacioppo, 1986), we hypothesized that because of limited resources there should be more auditory attention paid to the target tones during the reading of the nontailored nutrition message than during the reading of the tailored nutrition message. As a result, we predicted that the mean amplitudes of the N100 and P300 effects would be lower and that reaction times would be slower for the tailored than for the nontailored intervention group.

\section{Method}

\section{Participants and Experimental Design}

Twenty-nine psychology undergraduate students signed up for the experiment, 9 male students and 20 female students. They were 17 to 26 years of age $(M=21.38, S D=2.15)$; were native speakers of Dutch; were right-handed; and reported, on being asked, normal or corrected-to-normal vision and normal hearing. Participants were randomly exposed to either a tailored or nontailored nutrition education message about fat, vegetable, and fruit intake. Participants received course credits or a $€ 15$ (approximately \$18) gift voucher for their participation.

\section{Procedure, Materials, and Tasks}

The experiment had two sessions. In the first session, participants filled out written questionnaires that the researchers used to determine the students' fat, vegetable, and fruit intake as well as their attitude, selfefficacy, and intentions related to reducing their fat intake and increasing their consumption of fruits and vegetables (for a more elaborate description of the questionnaires, see Brug, Steenhuis, Van Assema, \& De Vries, 1996). The answers of the respondents in the tailored intervention group were used by Loes T. E. Kessels to construct an individually tailored nutrition message before the start of a second session approximately 1 week later.

In the second session, participants carried out a dual task. In addition to reading the nutrition education messages, they listened to sequences of high- and low-frequency tones and were to push a button whenever they heard the infrequent high-frequency tone (i.e., auditory oddball task; e.g., Hillyard et al., 1995). The EEG was recorded during the task. Therefore, after an electrode cap was mounted on the participant's head, he or she was taken to a dimly lit, sound-attenuating, electrically shielded cabin and seated in a comfortable chair approximately $80 \mathrm{~cm}$ from a computer screen that situated the participant at eye level to the screen's center. Participants were instructed to stay fixated on the nutrition information presented on the screen while performing the auditory oddball task and to avoid eye blinks and other body movements as much as possible during presentation of the intervention messages and auditory oddball task. It was also made clear to them that the reading task and oddball task were equally important and that both had to be performed accurately.

The participants in the tailored intervention group read the personrelated information, whereas the participants in the nontailored intervention group received a general message without any person-related information (see also Brug et al., 1998). For example, a person in the tailored intervention group who ate $100 \mathrm{~g}$ of fat/day read the following sentence: "You eat daily $100 \mathrm{~g}$ of fat, whereas $75 \mathrm{~g}$ is sufficient." In the nontailored intervention group, the sentence read was as follows: "On average people in the Netherlands eat $95 \mathrm{~g}$ fat per day, whereas $75 \mathrm{~g}$ is sufficient." The nontailored intervention message contained 1,923 words, the tailored in tervention messages contained between 1,900 and 2,100 words. Both messages had three sections referring to fat, vegetable, and fruit intake, respectively. 
To minimize eye movements, we presented the intervention messages on the computer screen word-by-word with an interstimulus interval of 1,000 ms. Every word appeared on the screen for $250 \mathrm{~ms}$, followed by a black screen for $750 \mathrm{~ms}$. The words were clearly visible and had a minimum length of 2 letters and a maximum length of 16 letters. In the auditory oddball task, the high- $(1,000 \mathrm{~Hz})$ and low-frequency $(500 \mathrm{~Hz})$ auditory tones were presented simultaneously with the words of the intervention messages. The tones were presented $150 \mathrm{~ms}$ after word onset, and the tone length was $100 \mathrm{~ms}$. The low- and high-frequency tones were presented in random order. The high-frequency tones (target stimuli) had an occurrence probability of $17 \%$, the low-frequency tones (nontarget stimuli) had an occurrence probability of $83 \%$. On hearing a high-frequency tone, participants responded as instructed by pressing the button as fast as possible. On hearing a low-frequency tone, no overt response was required. The oddball and reading tasks were preceded by a practice round of 50 oddball trials without word presentation and interrupted by two breaks of 2 min each.

After finishing the dual task, participants answered several self-report questions concerning message attention and evaluation and motivation to change. Finally, participants were debriefed, paid, and asked not to talk about the objectives and topic of the study with fellow students. The entire second session took about $2 \mathrm{hr}$.

\section{Measures}

Reaction times. Button-press responses were measured from high tone onset, with a time-out limit of $850 \mathrm{~ms}$.

EEG. The EEG was recorded from 30 scalp sites (an extended version of the 10/20 system) with tin electrodes mounted in an electrode cap, with the electrodes referenced to the left mastoid signal. A bipolar montage of two electrodes, one each placed on the right and left external canthus, recorded horizontal eye movements. Vertical eye movements and eye blinks were measured by a bipolar montage of two electrodes, one each placed on the upper and lower orbital ridge of the left eye. The electrooculogram was recorded for later off-line rejection of trials contaminated with eye movements. EEG and electro-oculogram signals were digitized at $250 \mathrm{~Hz}$ and amplified by using a 32-channel NeuroScan SynAmps (Compumedics Neuroscan, El Paso, Texas) amplifier with a bandpass of 0.05-30 Hz. All electrode impedances (EEG and electro-oculogram) were kept below $5 \mathrm{k} \Omega$.

N100 and P300 ERP. From the continuous EEG signal, epochs of 900 ms were obtained, including a $100 \mathrm{~ms}$ prestimulus (tone) baseline. Trials including artifacts were rejected from further analyses (threshold $+/-75$ $\mu \mathrm{V})$. By averaging the remaining artifact-free epochs per participant per condition, we derived the ERP waveforms separately for high- and lowfrequency tones in each intervention condition. Next, we computed difference waveforms per participant for each intervention condition by subtracting the ERP to the nontarget tones from the ERP to the target tones. The difference waveforms were quantified by mean amplitude measures $(\mu \mathrm{V})$ to assess the $\mathrm{N} 100$ effect (in the time window of $80 \mathrm{~ms}$ to $150 \mathrm{~ms}$ ) and P300 effect (in the time window of $230 \mathrm{~ms}$ to $450 \mathrm{~ms}$ ), respectively. The latency windows were derived from visual inspection of the grand average difference waves at the $\mathrm{Fz}$ electrode to determine the latency for the N100 effect across electrodes and at the Pz electrode to determine the latency for the P300 effect across electrodes (see Figure 1, right column). The analyses were restricted to the midline electrodes $\mathrm{Fz}, \mathrm{Cz}$, and $\mathrm{Pz}$ because the N100 and P300 effects are generally the largest for these midline electrodes.

Self-report. We used self-report items that had 7-point Likert scales and that were based on measures proposed by Brug et al. (1996) and Kreuter et al. (2000). We measured perceived attention (i.e., "to what extent have you read the information carefully," on a scale from $1=n o t$ at all to $7=$ very $m$ much), perceived difficulty of the information (i.e., "how difficult or easy was the content of the information," on a scale from $1=$ very difficult to $7=$ very easy), appreciation of the message (on scales from $1=$ unpleasant to $7=$ pleasant, $1=$ unattractive to $7=$ attractive, and
$1=$ uninteresting to $7=$ interesting; Cronbach's $\alpha=.81$ ), and perceived personal relevance of the nutrition message (with $1=$ not at all and $7=$ very much). Finally, in one item, we asked participants whether they intended to change their diet behavior on the basis of the information they had $\operatorname{read}(0=$ no and $1=$ yes $)$.

\section{Data Analysis}

Independent-samples $t$ tests were used to compare the two groups on the reaction times (millisecond) and the answers on the self-report questionnaires (for the dichotomous measure of intention, a logistic regression analysis was used). To examine whether the N100 and P300 attention effects were modulated by the intervention conditions, we subjected mean amplitude measures in the indicated time windows to repeated measures analyses of variance that crossed the between-subjects variable intervention (tailored vs. nontailored) and the within-subjects variable electrode sites (midline electrodes: $\mathrm{Fz}, \mathrm{Cz}$, and Pz). At sites where the P300 effect was at its maximum (anticipated $\mathrm{Cz}$ and $\mathrm{Pz}$ ), we used planned comparisons (i.e., independent-samples $t$ tests) to test the effect of intervention at each electrode site. We also included Fz to show that the effect has a centralparietal, and not frontal, distribution. Following visual inspection of the signal distribution of the N100 effect, we used a similar procedure for testing the effect of intervention at $\mathrm{Fz}, \mathrm{Cz}$, and $\mathrm{Pz}$ in the $80 \mathrm{~ms}-150 \mathrm{~ms}$ time window. To control for sphericity violations in the analyses of variance, we reported probability values with Greenhouse-Geisser correction for $F$ tests with more than one degree of freedom in the numerator. The reported estimates of the effect size are the partial eta squared $\left(\eta_{\mathrm{p}}^{2}\right)$ for the analyses of variance, Cohen's $d$ for the independent-samples $t$ tests, and odds ratio (OR) for the logistic regression analysis.

\section{Results}

Because the data sets of 3 participants in the tailored intervention group and 2 participants in the nontailored intervention group could not be used because of too many artifacts (more than $50 \%$ of the reactions to the high frequency tones were rejected) or because of technical problems, 24 participants remained in the sample and were included in the analyses, with 13 participants in the nontailored intervention group and 11 in the tailored intervention group.

\section{Premeasures}

Analyses showed that the tailored and nontailored intervention groups did not significantly differ on the measures of attitude, self-efficacy, intention, and behavior regarding fat, vegetables, and fruit intake that served as input for the nutrition messages ( $p \mathrm{~s}>$ .20 ), indicating that the randomization indeed resulted in equal groups.

\section{Error Analysis}

Trials in which no response was registered within $850 \mathrm{~ms}$ after presentation of the auditory target tone or in which a response was given in reaction to the nontarget tone were left out of the analyses of both the reaction time data and the ERP data. The proportion of rejected trials was not different between participants in the tailored intervention group $(M=.03 ; S D=.01)$ and those in the nontailored intervention group $(M=.03 ; S D=.01), t(22)=-0.90, p=$ $.38, d=-.37 ; 95 \%$ confidence interval $(\mathrm{CI}):-0.02,0.01$. Furthermore, we looked at the number of valid responses to the auditory target that could not be analyzed because of eye and other movements that distorted the resulting EEG signal and thus were 
Frequent nontarget tones

$\mathbf{F z}$
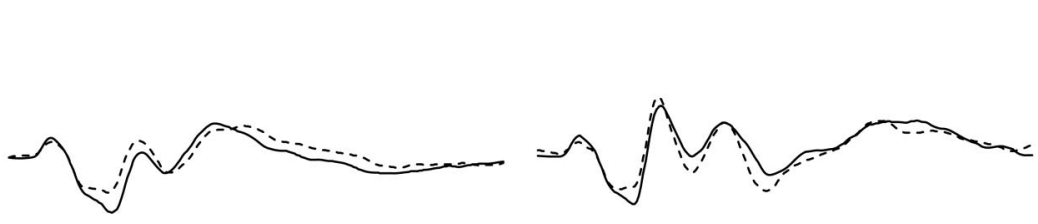

$\mathrm{Cz}$
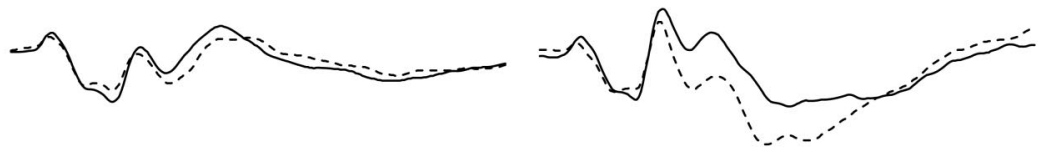

$\mu \mathrm{V}$

$\mathrm{Pz}$

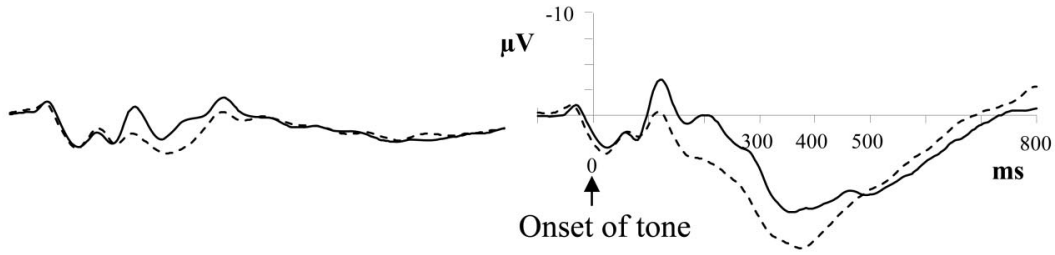

tailored

\section{Odd target tones}

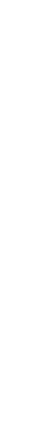

nontailored

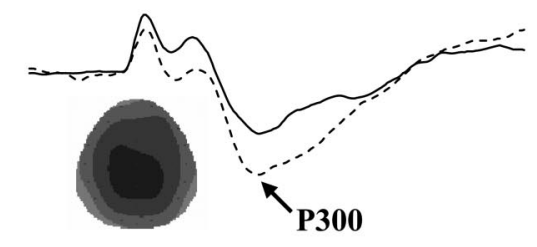

Difference waves

(target minus nontarget)
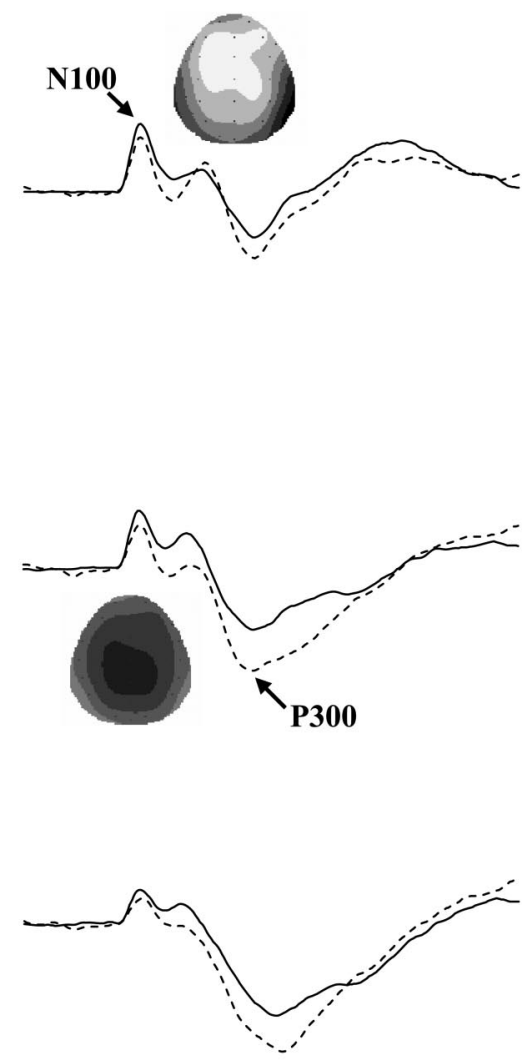

Figure 1. Grand average event-related potentials waveforms for tailored and nontailored intervention groups. Data are displayed for all 24 participants for the midline electrode sites Fz, Cz, and Pz. Negative voltage is plotted up along the $y$-axis. The topographical maps present the signal distributions of the N100 effect at $112 \mathrm{~ms}$ and the P300 effect at $320 \mathrm{~ms}$ after stimulus onset with a maximum of $5 \mu \mathrm{V}$ (black) and a minimum of $-5 \mu \mathrm{V}$ (white).

excluded from further analyses. This number of lost valid responses as a proportion of the total number of valid responses did not differ between the nontailored group $(M=.05 ; S D=.07)$ and the tailored group $(M=.05 ; S D=.05), t(22)=-0.08, p=.94$, $d=-.03$ (95\% CI: $-0.05,0.05)$.

\section{ERP}

Visual inspection. The grand average waveforms at the midline electrode sites (see Figure 1) indicate that responses to the nontarget tones (left column) were similar for both intervention groups, showing that both groups produced a comparable baseline ERP wave. In contrast, responses to the target tones (center column) were stronger for the nontailored group compared with the tailored intervention group. As a result, both groups differed in the strength of the N100 effect and P300 effect, as can be seen in the difference waves (right column). Detailed visual inspection of the difference waveforms shows a P300 effect between approximately
$230 \mathrm{~ms}$ and $450 \mathrm{~ms}$ after stimulus onset that is strongest at the central and parietal sites. At these sites, the difference wave is more positive in amplitude for the nontailored than for the tailored intervention group. In addition, a N100 effect is displayed beginning at about $80 \mathrm{~ms}$ and extending to about $150 \mathrm{~ms}$ after tone onset that is strongest at the frontal and central sites. At these sites, the difference waveform is more negative for the tailored group than for the nontailored intervention group.

Baseline ERP. Statistical analyses of the responses to the nontarget tones found no significant differences between the intervention groups in the N100 and P300 time windows ( $p$ s > .10). This suggests that the two groups were comparable in terms of baseline ERP signals.

P300 effect. Significant main effects of intervention, $F(1$, $22)=5.54, p<.05, \eta_{\mathrm{p}}^{2}=.20$, and electrode sites, $F(2,44)=$ 49.66, $p<.001, \eta_{\mathrm{p}}^{2}=.69$, and a nonsignificant interaction between both variables, $F(2,44)=2.07, p=.15, \eta_{\mathrm{p}}^{2}=.09$, were 
found on the mean amplitude of the P300 effect. At the three electrode sites, in line with our hypothesis and the visual inspection of the grand average waveforms, larger mean amplitudes of the P300 effect were found for the nontailored group compared with the tailored group (see Table 1). Independent-samples $t$ tests and calculated effect sizes at each electrode site suggest that the P300 effect was significantly modulated by the intervention at $\mathrm{Cz}$, $t(22)=2.46, p<.05, d=1.00$ (95\% CI: 0.55, 6.58), and Pz, $t(22)=2.02, p=.03$ (one-tailed), $d=.84$ (95\% CI: $-0.07,5.83$ ). Together with a nonsignificant effect at Fz, $t(22)=1.42, p=.17$, $d=.59$ (95\% CI: $-0.59,3.11)$, these findings indicate a centralparietal distribution of the P300 effect, as is also illustrated by the topographical map of the signal distribution of the P300 effect at $320 \mathrm{~ms}$ after stimulus onset (see Figure 1).

N100 effect. Significant main effects of intervention, $F(1$, $22)=4.59, p<.05, \eta_{\mathrm{p}}^{2}=.17$, and electrode sites, $F(2,44)=$ $59.22, p<.001, \eta_{\mathrm{p}}^{2}=.73$, and a nonsignificant interaction effect, $F(2,44)=2.76, p=.09, \eta_{\mathrm{p}}^{2}=.11$, were found on the amplitude of the N100 effect. In line with the topographical map of the signal distribution of the N100 effect at $112 \mathrm{~ms}$ after stimulus onset (see Figure 1), independent-samples $t$ tests showed that the N100 effect was significantly modulated by the intervention at $\mathrm{Fz}, t(22)=$ $2.32, p<.05, d=.95$ (95\% CI: 0.13, 2.28), and Cz, $t(22)=2.23$, $p<.05, d=.90$ (95\% CI: 0.09, 2.54), but not at Pz, $t(22)=1.50$, $p=.15, d=.61(95 \% \mathrm{CI}:-0.26,1.64)$. Results thus indicate a frontal-central distribution. However, in contrast to our hypothesis and in support of the visual inspection of the grand average difference waves, the amplitudes of the N100 effect at Fz and Cz were higher for the tailored intervention group than for the nontailored intervention group (see Table 2).

\section{Reaction Times}

The nontailored intervention group seemed to react faster to the target tones $(M=343, S D=38)$ than the tailored intervention group $(M=363, S D=33)$. However, this difference was not significant, $t(22)=-1.39, p=.18, d=-.57$ (95\% CI: -50.25 , 9.99).

\section{Questionnaire Measures}

In line with the objectives of a tailored intervention message, participants in the tailored group evaluated the nutrition information as more personally relevant $(M=4.64 ; S D=1.15)$ than

Table 1

Mean Amplitudes in $\mu V$ of the P300 Effect

\begin{tabular}{|c|c|c|c|c|}
\hline \multirow[b]{3}{*}{ Electrodes } & \multicolumn{4}{|c|}{ Intervention } \\
\hline & \multicolumn{2}{|c|}{ Nontailored } & \multicolumn{2}{|c|}{ Tailored } \\
\hline & $M$ & $S D$ & $M$ & $S D$ \\
\hline $\mathrm{Fz}$ & 2.55 & 2.48 & 1.29 & 1.73 \\
\hline $\mathrm{Cz}$ & 7.21 & 3.26 & 3.65 & 3.86 \\
\hline $\mathrm{Pz}$ & 9.11 & 3.78 & 6.24 & 3.07 \\
\hline
\end{tabular}

Note. The table shows the $\mathrm{P} 300$ effect $(230 \mathrm{~ms}-450 \mathrm{~ms})$ for the nontailored and tailored intervention groups at the midline electrodes $\mathrm{Fz}, \mathrm{Cz}$, and $\mathrm{Pz}$.
Table 2

Mean Amplitudes in $\mu V$ of the N100 Effect

\begin{tabular}{clllll}
\hline & \multicolumn{4}{c}{ Intervention } \\
\cline { 2 - 4 } & \multicolumn{2}{c}{ Nontailored } & & \multicolumn{2}{c}{ Tailored } \\
\cline { 2 - 5 } \cline { 5 - 6 } Electrodes & $M$ & $S D$ & & $M$ & $S D$ \\
\hline $\mathrm{Fz}$ & -2.77 & 1.22 & & -3.97 & 1.31 \\
$\mathrm{Cz}$ & -2.25 & 1.09 & & -3.56 & 1.77 \\
$\mathrm{Pz}$ & -1.51 & 0.94 & -2.20 & 1.30 \\
\hline
\end{tabular}

Note. The table shows the $\mathrm{N} 100$ effect $(80 \mathrm{~ms}-150 \mathrm{~ms})$ for the nontailored and tailored intervention groups at the midline electrodes $\mathrm{Fz}, \mathrm{Cz}$, and Pz.

participants in the nontailored group $(M=3.38 ; S D=1.39)$, $t(22)=-2.37, p<.05, d=-.99$ (95\% CI: $-2.35,-0.16)$. Moreover, a larger proportion of participants in the tailored (63\%) as opposed to the nontailored (23\%) intervention group intended to change their diet behavior after reading the intervention message, Wald $(1)=3.77, p=.05$ (OR $=5.83$; 95\% CI: 0.98, 34.64). On the other self-report measures no significant differences between the two groups were found $(p s>.34)$.

\section{Discussion}

In an innovative research paradigm for both health education research and cognitive neuroscience, we found first ERP support for our hypothesis that personally-relevant information motivates people into more attentive information processing. As predicted, the observed P300 attention effects at central-parietal sites, which reflect attention allocation to the auditory task in a relatively late stage of information processing (i.e., at the interface between sensory and memory processing), were higher for the participants who read the nontailored nutrition message than for those who read the tailored message. On the basis of the assumption of resource allocation (Kok, 1997; Sanders, 1997), these modulations of the P300 effect thus suggest that the tailored information receives more attention from the participants than the nontailored information. Support for our hypothesis was also observed in the reaction time data. Although the reaction times did not significantly differ between participants in the tailored intervention group and those in the nontailored intervention group, the means were in the predicted direction (faster for nontailored compared with the tailored group - presumably because of attention allocation) and a medium-to-large effect size (Cohen, 1988) was reported.

We further found a frontally distributed N100 effect. However, and unexpected to us, the observed pattern of this effect, which we interpret as reflecting maintenance of early selection (Kok, 1997), was such that the effect was larger for the tailored than for the nontailored groups. We can only speculate here. A possible explanation for the observed N100 pattern could be that participants in the tailored group felt more involved with the study because they received personal relevant information, which conclusion was also supported on the self-report measure. Participants in the tailored group, compared with those in the nontailored group, may have been more motivated to read the message thoroughly and to perform well on the auditory oddball task, and those motivated performances were reflected in higher frontally distributed N100 
amplitudes. As a consequence of this better maintenance of selection, the integration of the selected information and the participants' general knowledge of health behavior in working memory then needs less effort, usually reflected in a smaller P300. This pattern is exactly what we observed. Alternatively, the increase of the N100 effect in the tailored group could be the result of a generalized increase of arousal in that condition as compared with the nontailored group. Earlier studies of the N100 found increases in amplitude with increases in arousal (see Näätänen, 1992).

In sum, the data give new empirical evidence for previous explanations of the positive effects of computer-tailored health messages that referred to the relative gain in attention for individualized health information but were only indirectly supported by self-report measures that followed exposure to the stimulus information (e.g., Brug et al., 1998). The data further support dual process models of attitude change that hold that personally relevant information is more systematically processed than information that is less self-relevant (e.g., Petty \& Cacioppo, 1986). Attentive processing of provided information, in turn, is an essential condition for effective health communication (McGuire, 1985). This is also supported by our finding that, in line with previous studies (for a review, see Brug \& De Vries, 1999), participants are more motivated to change their diet behavior after reading the personalized nutrition message than after reading the general nutrition message. It is remarkable that in this study we did not find a significant difference in subjective estimates of the extent to which respondents read the information carefully. The N100 and P300 data may thus point to the benefit of using more direct measures of important psychological processes (such as ERP on attention) that are conditional to the effectiveness of health communications.

Before we close, a number of potential limitations of this study should be noted. First, this study used a between-subjects experimental design. Although it provided us the opportunity to include subjective measures of message attention and evaluation and motivation, and although data suggested that both groups were similar in baseline ERP signals, the use of a within-subjects design, instead, would have had important advantages as well. A withinsubjects design would not only have increased the statistical power of this study by reducing the interperson variability but would also have eased the interpretation of the ERP data in terms of the extent to which the tailored information, relative to the nontailored information, resulted in drawing attention away from the auditory task.

Second, the relatively small sample size may have rendered the behavioral measure insufficiently sensitive to detect statistically significant differences between experimental conditions. Indeed, the lack of significant support on the reaction time measure despite the relatively large effect size reported may simply indicate a case of Type II error. It should be noted, however, that reaction times are indicative of the complete information process from stimulus processing to execution. It could be the case that, in one of those information processing stages, attention to the tailored information indeed slowed down the auditory information process, whereas this might later be washed out because of executive control effects that might be going in the other direction. (This problem of interpretation cannot be solved by just reaction time information.) This indicates that EEG can be extremely informative because we can look at processing phases prior to execution.
A third limitation concerns the presenting of the intervention text in a word-by-word format. Indeed, normal reading may occur in larger chunks than one word and may be faster (or slower) than the speed urged on participants in this study. However, the format we applied is widely used in ERP language-processing research, in which reading performance is a core target of investigation, because it reduces eye movements and makes data analysis possible in the first place. Of course, the presentation mode might affect sentence integration, by, for example, putting more load onto working memory (participants cannot look back in the text), but this should hold for all conditions in the experiment. The selfreport data at least shows that participants' appreciation and the perceived difficulty of the nutrition message were not different for the two intervention conditions.

Finally, we would like to point out that the interpretation of the data is based on the assumption of resource allocation theories and that our results are only a first step toward a deeper understanding of attentional processing during tailored versus nontailored message encoding. However, considering these limitations, this study provides first online (i.e., during message exposure) empirical evidence that personalized health messages may attract more attention than nontailored health messages, and thus this study contributes to the further dismantling of the working mechanisms of effective computer-tailored health communications.

\section{References}

Brug, J., \& De Vries, H. (Eds.). (1999). Computer-tailored education [Special issue]. Patient Education Counseling, 36(2).

Brug, J., Glanz, K., Van Assema, P., Kok, G., \& Van Breukelen, G. J. P. (1998). The impact of computer-tailored feedback and iterative feedback on fat, fruit, and vegetable intake. Health Education and Behavior, 25, $517-531$.

Brug, J., Oenema, A., \& Campbell, M. K. (2003). Past, present, and future of computer-tailored nutrition education. American Journal of Clinical Nutrition, 77(Suppl. 4), 1028S-1034S.

Brug, J., Steenhuis, I., Van Assema, P., \& De Vries, H. (1996). The impact of a computer-tailored nutrition intervention. Preventive Medicine, 25, $236-242$.

Cohen, J. (1988). Statistical power analysis for the behavioral sciences (2nd ed.). Hillsdale, NJ: Erlbaum.

Coull, J. T. (1998). Neural correlates of attention and arousal: Insights from electrophysiology, functional neuroimaging and psychopharmacology. Progress in Neurobiology, 55, 343-361.

Dijkstra, A., \& De Vries, H. (1999). The development of computergenerated tailored interventions. Patient Education and Counseling, 36, 193-203.

Fabiani, M., Gratton, G., \& Coles, M. G. H. (2000). Event-related brain potentials. In J. T. Cacioppo, L. G. Tassinary, \& G. G. Berntson (Eds.), Handbook of psychophysiology (2nd ed., pp. 53-84). New York: Cambridge University Press.

Hillyard, S. A., Mangun, G. R., Woldorff, M. G., \& Luck, S. J. (1995) Neural systems mediating selective attention. In M. S. Gazzaniga (Ed.), The cognitive neurosciences (pp. 665-681). Cambridge, MA: MIT Press.

Kok, A. (1997). Event-related potential (ERP) reflections of mental resources: A review and synthesis. Biological Psychology, 45, 19-56.

Kramer, A. F., Wickens, C. D., \& Donchin, E. (1985). The processing of stimulus properties: Evidence for dual task integrality. Journal of Ex- 
perimental Psychology: Human Perception and Performance, 11, $393-$ 408.

Kreuter, M. W., Farrell, D., Olevitch, L., \& Brennan, L. (2000). Tailoring health messages: Customizing communication with computer technology. Mahwah, NJ: Erlbaum.

Mangun, G. R., \& Hillyard, S. A. (1995). Mechanisms and models of selective attention. In M. D. Rugg \& M. G. H. Coles (Eds.), Electrophysiology of mind: Event-related brain potentials and cognition (pp. 40-85). Oxford, England: Oxford University Press.

McGuire, W. J. (1985). Attitudes and attitude change. In G. Lindzey \& E.
Aronson (Eds.), The handbook of social psychology (Vol. 2, pp. 233 346). New York: Random House.

Näätänen, R. (1992). Attention and brain function. Hillsdale, NJ: Erlbaum. Petty, R. E., \& Cacioppo, J. T. (1986). Communication and persuasion: Central and peripheral routes to attitude change. New York: SpringerVerlag.

Sanders, A. F. (1997). A summary of resource theories from a behavioral perspective. Biological Psychology, 45, 5-18.

Wilson, T. D. (2002). Strangers to ourselves: Discovering the adaptive unconscious. Cambridge, MA: Belknap Press. 